Journal of Research in Interprofessional

Practice and

Education

Vol. 6.2

2016

\title{
A Cross-Comparative Study to Examine Beliefs and Attitudes Regarding Food and Eating between Food and Nutrition and Social Work Students
}

\author{
Colleen McMillan, PhD, RSW \& Janet Madill, PhD, RD
}

\begin{abstract}
Background: Little is known regarding attitudes and beliefs toward eating disorders by students interested in working with this population. This study aims to understand similarities and differences between food and nutrition and social work students regarding their attitudes and beliefs toward food and eating, and how these findings may inform curriculum development prior to graduation as well as practice in the field.

Methods and Findings: Using a mixed-method approach, 14 social work (SW) and 26 food and nutrition (FN) students completed the Eating Disorders Attitudes Questionnaire (EAT-26) and participated in focus groups. After viewing 33 photographs of 11 different foods displayed as small, normal, and large portions according to Canada's Food Guide, students categorized portions followed by their rationale. Different symptoms of disordered eating emerged; choices by FN students were informed by clinical knowledge and internal tension, whereas choices by SW students were based on external influences including industry, family, and cultural expectations. Language was noticeably different; FN students used clinical language creating distance between themselves and the photos, versus SW students who spoke from a personal and affective standpoint.

Conclusions: Understanding attitudes and beliefs concerning food and eating by students planning to work with eating disorder clients raises questions of possible professional competencies and curriculum development prior to entering this practice area.
\end{abstract}

Keywords: Interprofessional practice; Nutrition; Social work; Curriculum; Eating disorders

\section{Introduction}

The prevalence of eating disorders is increasing for Canadians in general, with more

Journal of Research in Interprofessional Practice and Education (JRIPE)

Vol. 6.2

(c) 2016

Corresponding author: Colleen McMillan. Email: c7mcmill@uwaterloo.ca of these cases being addressed within primary care as compared to hospital settings. In 2006, policy changes by the Ontario government resulted in an infusion of capital into supporting eating disorder programs within community-based settings. One of the stipulations accompanying the fiscal investment was the creation of treatment services including an interdisciplinary team comprised of professionals from psychology, nutrition/dietetics, nursing, occupational therapy, and social work [1]. Several years later, the same provincial government established a model of primary 
2

Social Work Students' Food Beliefs

McMillan \& Madill

Journal of Research in Interprofessional Practice and Education

Vol. 6.2

2016 healthcare through the creation of family health teams and community health organizations. These healthcare sites are also guided by mission statements that support an interdisciplinary model of practice with a dietitian and social worker being integral members of the healthcare team. According to the College of Dietitians and the Canadian Association of Social Workers, a high percentage of graduates from these two professions will be entering the healthcare field, with many of these graduate students expressing interest in working with the eating disordered population [2]. The attitudes and beliefs around food and eating held by graduate students who intend to work with this population is not known. Current literature points to studies that have found disordered eating risk factors and behaviours among university populations [3] -female university athletes [4], female dietetic students [4-11], home economic students [12]. Race is also a factor [13]. However, a meta-review found few comparative studies that explored cross-disciplinary differences among undergraduate students between psychology, physical education, pharmacy, nursing, nutrition, dentistry and medicine [14]. As well, few studies have explored bulimia among dietitians, nurses, and teachers [15]; nutrition and non-health students [16]; and nursing, medical, and arts students [17]. A review of the literature from 1990 to 2016 found no studies exploring eating disorders between social work and food and nutrition student populations.

Several similarities apply to food and nutrition (FN) and social work (SW) students; both are predominately female professions. As such, gender may play a role in attitudes and beliefs around food and eating that are socially constructed. Secondly, the spectrum of problematic eating from disordered eating to eating disorders is addressed within the curriculum in both programs, albeit from different epistemological paradigms. Understanding and knowing if there are differences and similarities between these two groups of students is important for several reasons. The first concerns the suitability of students who enter clinical positions on interprofessional eating disorder teams upon graduation. A lack of awareness regarding attitudes and beliefs suggestive of risk factors for problematic eating, or what Stephen Szweda and Pam Thorne refer to as "anorexic and bulimic tendencies," [17, p. 114] may result in biased or personally informed treatment decisions when working with an already vulnerable patient population. If such attitudes and beliefs do exist, and remain unaddressed, the potential for negative dynamics on the interprofessional team increases, complicating team cohesion between healthcare providers already challenged with treating clinically complex issues associated with eating disorders. In addition to suitability, a second related issue pertains to the role expected of dietitians and social workers on an interprofessional team. Christina Reiter and Leah Graves describe the dietitians' role as one to address food selection and portion size toward the goal of "normalization of eating" [18, p. 132] including that of social eating. Likewise, the role of the social worker is to identify and manage the complex counter-transference dynamics within the therapeutic relationship that can impede treatment progress [19]. Both roles require a high degree of continuous interpersonal awareness and reflexivity to separate personal issues from professional ones and to function as an effective team member. 
3

Social Work Students' Food Beliefs

McMillan \& Madill

Journal of Research in Interprofessional Practice and Education

Vol. 6.2

2016

\section{Method}

A mixed-method approach was chosen for this study for reasons of rigour, utility, and transferability. Mixed-method criteria requires qualitative and quantitative data sets, integration of data sets regarding "comparing, contrasting or embedding conclusions" [20, p. 210], and makes a meaningful contribution to emerging literature.

\section{Participant recruitment}

Research ethics was obtained from the University of Waterloo [ORE \#18793], Waterloo, ON, and the University of Western Ontario [REB\#10469], London, ON. Consenting participants were recruited using posters from the respective universities. A general information session to potential participants was given by the researchers at both sites. If interested, a participant contacted the site-specific trained peer-research assistants who facilitated the focus groups. In total 26 fourth-year students (25 female and one male) from FN at Brescia University College (BUC), University of Western Ontario, and 14 fourth-year female students from SW at Renison University College (RUC), University of Waterloo, participated in the study. All four peer research assistants received in-depth training on focus group facilitation, specifically about asking of sensitive questions, informed consent, and confidentiality, prior to running six focus groups.

\section{Mixed-method approach}

The overarching research proposal, "A Cross Comparative Study of Attitudes and Beliefs Around Food and Eating between SW and FN Students," was intentionally constructed to reflect the hybrid of qualitative and quantitative inquiry, and subsequently broken down to reflect the two different research strands [21]. The two subquestions were:

Are there differences and similarities between SW and FN nutrition

undergraduate students regarding their attitudes and beliefs about

disordered eating?

What do the descriptions on food portions tell us about these similarities and differences between the two professions?

The pair of nested sub-questions "sets the stage for comprehensive mixed methods inferences and conclusions" [20, p. 210] at the end of the study, resulting in richer, more nuanced explanations of the meanings the participants associated with the different food groups.

Content for the focus groups involved four sequential components. The first component comprised a self-reported demographic questionnaire with questions relating to height, weight, age, gender, and activity level. Participants then completed the validated Physical Activity Questionnaire adapted from Canadian Physical Activity guidelines for adults 18-64 years [22]. The third component was the Eating Attitudes Test-26 Questionnaire (EAT-26), a validated and widely used standardized selfreport measure of symptoms and concerns characteristic of eating disorders [23,24] (see Table 1). It was emphasized to the participants that the use of the EAT-26 was 


\section{JRIPE}

4

Social Work Students' Food Beliefs

McMillan \& Madill

Journal of Research in Interprofessional Practice and Education

not for diagnostic purposes but rather as a way to identify their underlying attitudes and beliefs around food and eating. Lastly, the participants were given actual photographs of different foods divided into small, normal, and large portions as determined by Eating Well for Healthy Canadians [22]. They were asked to pick out what they thought represented a normal portion size for someone similar to their demographic profile. All six focus groups were given identical pictures of the following 11 foods: a plain bagel, a slice of banana cake, a glass of orange juice, a single-size portion of plain yogurt, one serving of spaghetti, a chicken wrap, a garden salad, scrambled eggs, a latte, breaded chicken fingers, and a plate of fries. All of the foods were selected from the cafeterias of the two universities to replicate typical choices available to the study population. Once the participants categorized the pictures into the "normal" group, they were asked to discuss their reasons with the facilitators, who emphasized that there was no right or wrong answer.

\section{Table 1. Eating Attitudes Test-26 (EAT) Questionnaire}

Please check a response for each of the following statements:

1. Am terrified about being overweight.

2. Avoid eating when I am hungry.

3. Find myself preoccupied with food.

4. Have gone on eating binges where I feel that I may not be able to stop.

5. Cut my food into small pieces.

6. Aware of the calorie content of foods that I eat.

7. Particularly avoid food with a high carbohydrate content (i.e., bread, rice, potatoes, etc.)

8. Feel that others would prefer if I ate more.

9. Vomit after I have eaten.

10. Feel extremely guilty after eating.

11. Am preoccupied with a desire to be thinner.

12. Think about burning up calories when I exercise.

13. Other people think that I am too thin.

14. Am preoccupied with the thought of having fat on my body.

15. Take longer than others to eat my meals.

16. Avoid foods with sugar in them.

17. Eat diet foods.

18. Feel that food controls my life.

19. Display self-control around food.

20. Feel that others pressure me to eat.

21. Give too much time and thought to food.

22. Feel uncomfortable after eating sweets.

23. Engage in dieting behaviour.

24. Like my stomach to be empty.

25. Have the impulse to vomit after meals.

26. Enjoy trying new rich foods.
Behavioural questions:

In the past months you have:

Gone on eating binges where you feel that you may not be able to stop?*

Ever made yourself sick (vomited) to control your weight or shape?

Ever used laxatives, diet pills or diuretics (water pills) to control your weight or shape?

Exercised more than 60 minutes a day to lose or to control your weight?

Lost 20 pounds or more in the past 6 months

* Defined as eating much more than most people would under the same circumstances and feeling that eating is out of control. Source: EAT-26 [22]. 
5

Social Work Students' Food Beliefs

McMillan \& Madill

Journal of Research in Interprofessional Practice and Education

Vol. 6.2

2016
The EAT-26 is a common screening tool to assess eating disorder risk in general populations, including those of high school and postsecondary groups [25]. It has been used over other measures, such as the SCOFF Questionnaire, because of its higher sensitivity [26] to identify risk behaviours among university populations $[16,6,8]$. The EAT-26 has been used as a screening questionnaire in non-clinical populations [22]. For purposes of participant ease, the EAT-26 was chosen over the longer form of the EAT-40.

Twenty-six items form three subscales in the EAT-26: dieting, bulimia and food preoccupation, and oral control. Items are rated on a scale from 1 (never) to 6 (always). Subscale scores are computed by summing all items assigned to that particular scale (dieting scale items: $1,6,7,10,11,12,14,16,17,22,23,24,25$; bulimia \& food preoccupation scale items: $3,4,9,18,21,26$; oral control subscale items: $2,5,8$, $13,19,20)$.

As mentioned, we emphasized to the participants that the purpose of using the EAT-26 was not as a diagnostic tool but rather a tool that would tell the researchers more about participant attitudes and beliefs toward eating and food prior to entering the workforce. Our stated purpose was to explore whether eating disorder tendencies existed within and between the two student groups, not to have a diagnosis as a study outcome.

\section{Transcription and analysis}

Discussions from the six focus groups were captured on a digital recorder. During the transcription the participants' names were removed and they were assigned a number for reasons of anonymity. The focus group discussions were transcribed verbatim by only one of the facilitators at each site to ensure consistency and continuity with the data [27]. The transcriptions were then given to the primary researchers who coded them line by line to remain close to the data, be sensitive to the emerging themes, and remain congruent with the guidelines for the immersion-crystallization method [28]. After line coding, the two researchers compared themes for the purposes of inter-rater reliability looking for discrepancies. When a possible discrepancy was discovered, the researchers jointly returned to the transcriptions to explore alternative interpretations, in addition to soliciting the facilitators' perspective of the specific focus group where the data originated. This cross-checking was also an attempt to be mindful of bias and reflectivity on the part of the two primary researchers, who have extensive clinical practice with the eating disordered population in both hospital and primary care settings over the past 25 years.

Each focus group transcription was coded independently, with two iterations, by both primary researchers to reflect the immersion phase. The first iteration focused on descriptive words used by the participants specific to each food item (see Table 2 and Table 3). The second iteration organized the participants' rationale used to categorize the photos into general themes, which were then compared between the two groups of students (see Figure 1 and Figure 2). Contents in tables and figures make transparent the coding iterations and the collapsing of themes. 


\section{JRIPE}

6

Social Work Students' Food Beliefs

McMillan \& Madill

Journal of Research in Interprofessional

Practice and Education

Vol. 6.2

2016

\section{Table 2. Explanations by social work students in choosing a normal portion}

\begin{tabular}{|c|c|}
\hline Bagel & $\begin{array}{l}\text { It's what I feel comfortable with. } \\
\text { When you order a bagel they give you a large, so I guess that is normal. }\end{array}$ \\
\hline Banana Cake & $\begin{array}{l}\text { I eat based on what feels comfortable. } \\
\text { This is the size I get in a restaurant. } \\
\text { I would say this size (large) based on what I am served in a restaurant. }\end{array}$ \\
\hline Orange Juice & $\begin{array}{l}\text { I feel better about drinking the large size - so that would be my normal. } \\
\text { This is the size (large) that I am served when I eat out. } \\
\text { My boyfriend who is diabetic says a small size is normal, so, yeah ... I really don't know- } \\
\text { the size that I get at the farmers' market is normal. } \\
\text { If it is } 100 \text { percent orange juice I choose the large size as normal because I feel it's healthier. }\end{array}$ \\
\hline Yogurt & $\begin{array}{l}\text { I don't worry about what is normal—-the package does that for me. } \\
\text { The package tells you what is a normal serving—it takes the guess work out. }\end{array}$ \\
\hline Spaghetti & $\begin{array}{l}\text { I feel like I want to be healthier — so I would choose the medium one. } \\
\text { The large portion is what you get in a restaurant. } \\
\text { This is a healthy food so I would go with the larger portion. }\end{array}$ \\
\hline Chicken Wrap & When I eat out you get two — so that is what I consider to be normal. \\
\hline Salad & $\begin{array}{l}\text { Salad is good for you so I eat a large one. } \\
\text { We are German so we eat salad at the end of the meal—-so it would be this size [medium]. } \\
\text { Avocado is like a piece of meat—so I would choose this one [small]. }\end{array}$ \\
\hline Scrambled Eggs & $\begin{array}{l}\text { Eggs are protein so I would eat the large portion. } \\
\text { We don't eat eggs alone - in my culture we only eat eggs with bread—-so the small portion is nor- } \\
\text { mal. } \\
\text { When I order an omelette in a restaurant they give this portion [large]. }\end{array}$ \\
\hline Latte & $\begin{array}{l}\text { I feel the medium is the normal portion because of the calories. } \\
\text { I always get the large size even though I feel guilty about the calories. } \\
\text { Probably the small is the right answer, but I always get the large. }\end{array}$ \\
\hline Chicken Fingers & I get four in a restaurant-which I feel is normal. \\
\hline French Fries & $\begin{array}{l}\text { I live with a lot of men so I would say the large is normal. } \\
\text { If I go to a fast-food restaurant I always order the large. } \\
\text { I haven't ate [sic] French fries ... for almost } 14 \text { to } 15 \text { days ... but I order the large because } \\
\text { they are like a treat for me. }\end{array}$ \\
\hline
\end{tabular}




\section{JRIPE}

7

Social Work Students' Food Beliefs

McMillan \& Madill

Journal of Research in Interprofessional Practice and Education

Vol. 6.2

2016

\section{Table 3. Explanations by food and nutrition students in choosing a normal portion}

\begin{tabular}{|c|c|}
\hline Bagel & $\begin{array}{l}\text { I know that according to Canada's food guide half a bagel is a serving, so that is what I would } \\
\text { say is a normal portion. } \\
\text { So, I say what I would normally eat ... or what I SHOULD eat? } \\
\text { I would probably eat the whole bagel, but based on what I know from Canada's Food Guide, } \\
\text { the recommended portion serving size is } 160 \mathrm{~g} \text { like at Tim Horton's they give you the full bagel, } \\
\text { but I will only eat half of it. } \\
\text { We're trained to think a certain way ... but in reality, I am likely to eat the whole bagel. }\end{array}$ \\
\hline Banana Cake & $\begin{array}{l}\text { If I went to Starbucks and bought that, I would have a really hard time only eating half which } \\
\text { is the correct portion size and just chucking the rest. } \\
\text { It reminds me of something you would order in a restaurant-you look at it and think—God, } \\
\text { I can't eat that. }\end{array}$ \\
\hline Orange Juice & $\begin{array}{l}\text { Well, based on Canada's Food Guide, I would say this one is normal, even though that's a very small } \\
\text { amount. } \\
\text { If you were to give someone half a glass of orange juice in a restaurant, well ... even though } \\
\text { this is what Canada's Food Guide says ... it's just a shot of orange juice. }\end{array}$ \\
\hline Yogurt & $\begin{array}{l}\text { I believe this one is normal basing [it] on the yogurt serving sizes from Canada's Food Guide. } \\
\text { I would personally take the smallest serving because it is Greek yogurt and its very rich. }\end{array}$ \\
\hline Spaghetti & $\begin{array}{l}\text { I think normal people would probably eat more than that. Like what they get at restaurants. } \\
\text { At a restaurant you are getting at least } 4 \text { servings. } \\
\text { I would say the smallest one's normal because on Canada's Food Guide it's a very small serving } \\
\text { what else are they eating for dinner? You might have a salad on the side—or just spaghetti } \\
\text { without the meatballs... so it depends. }\end{array}$ \\
\hline Chicken Wrap & $\begin{array}{l}\text { When I think about wraps coming from a restaurant ... it's ridiculous—you should only be } \\
\text { eating half for sure. }\end{array}$ \\
\hline Salad & $\begin{array}{l}\text { If this was the only meal, I would say this is normal, but it comes down to what else } \\
\text { accompanies it, what kind of dressing is on it. } \\
\text { This would be a meal [pointing to the large]. }\end{array}$ \\
\hline Scrambled Eggs & $\begin{array}{l}\text { Two eggs is a normal portion according to Canada's Food Guide this is excessive [pointing to } \\
\text { large] unless I was at a restaurant. }\end{array}$ \\
\hline Latte & $\begin{array}{l}\text { You know a drink is a snack. } \\
\text { So for me the smallest one is normal—unfortunately its not for most people. } \\
\text { I know how many calories are in these things—-if I wanted } 600 \text { calories I would eat the } \\
\text { chicken fingers. }\end{array}$ \\
\hline Chicken Fingers & $\begin{array}{l}\text { I love chicken fingers but being a nutrition student I would never order them. } \\
\text { I know that } 75 \mathrm{~g} \text { is a normal protein serving, so the middle plate would be normal, the scary } \\
\text { part is that this would be a normal serving for someone [pointing to large]. } \\
21 \frac{12}{2} \text { ounces or so is normal. } \\
\text { I never make chicken fingers at home_-but I would feel jipped [sic] if I got that one at a } \\
\text { restaurant [pointing to small portion]. }\end{array}$ \\
\hline
\end{tabular}




\section{JRIPE}

8

Social Work Students' Food Beliefs

McMillan \& Madill

\section{Table 3. (continued)}

\begin{tabular}{|l|l}
\hline French Fries & $\begin{array}{l}\text { If I were to go out with friends I could eat this no problem [large]_as compared at home when } \\
\text { you are more conscious. } \\
\text { I may be eating that [small portion], but I want to be eating that [large portion]. } \\
\text { Based on Canada's Food Guide it should be the smallest one. But, in a normal setting, people } \\
\text { will be eating that [large portion]. } \\
\text { If my parents made fries I would eat that [smaller portion], but if I was at a restaurant I would } \\
\text { be ordering that [largest portion]. }\end{array}$
\end{tabular}

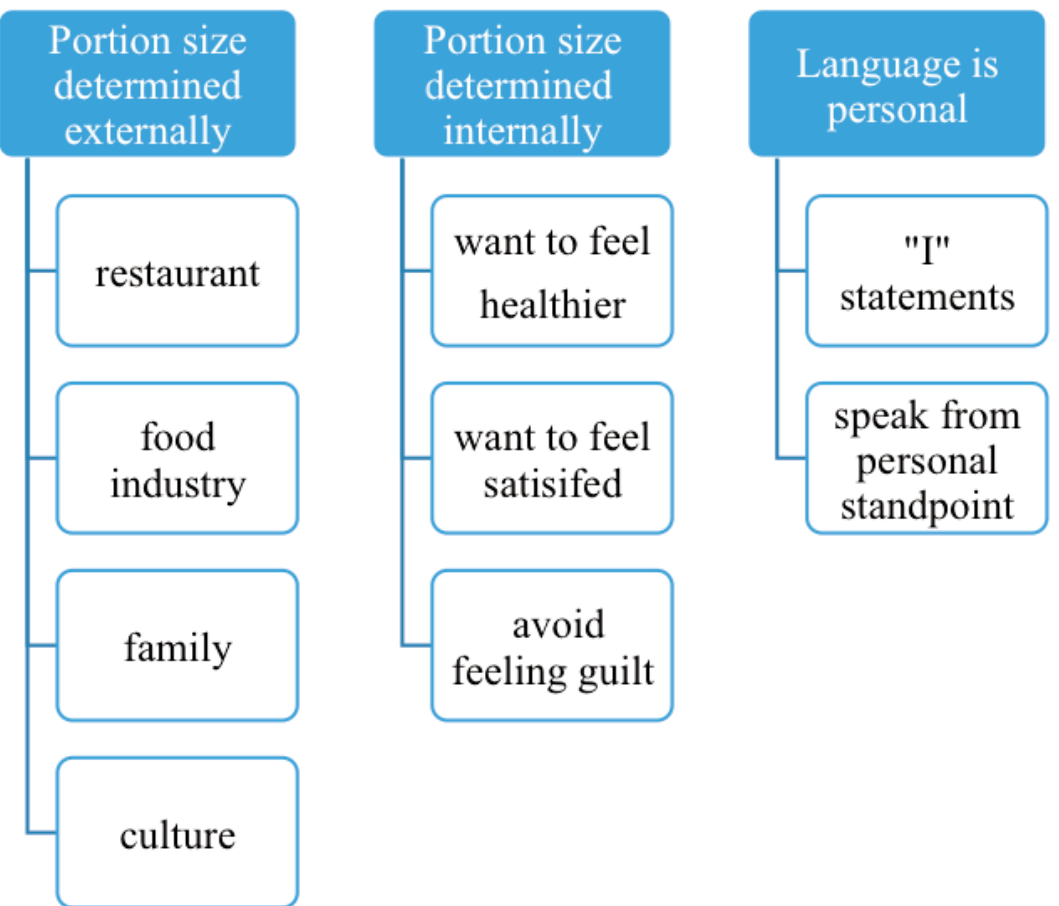

Figure 1. Collapsing of codes for social work students

Journal of Research in Interprofessional

Practice and

Education
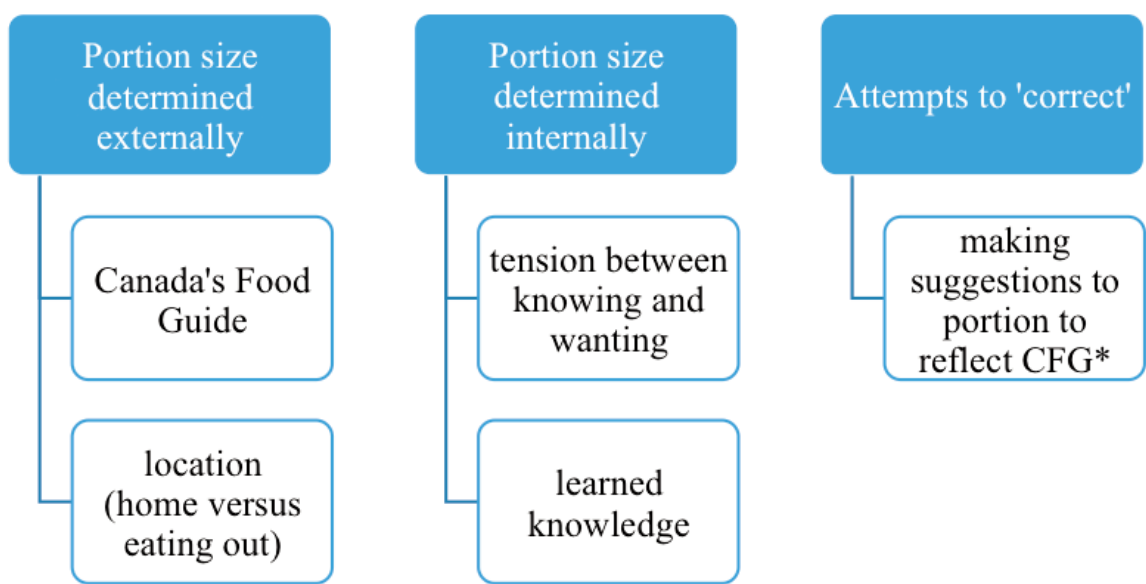

Figure 2. Collapsing of coding for FN students

*Canada's Food Guide 


\section{Journal of Research in Interprofessional Practice and Education}

Once the immersion stage was completed, the researchers engaged in the analytic stage of crystallization, described as "the process of temporarily suspending the process of examining or reading the data in order to reflect on the analysis experience and attempt to identify and articulate patterns or themes noticed during the immersion process" [29, p. 183]. Allowing this space supported discussions between the two authors, giving them the opportunity to reflect upon how their diverse paradigms of education and practice informed their approach to the data. Natasha Mauthner, Odette Parry and Kathryn Backett-Milburn strongly support such a space to allow for reflexivity by the researcher, which gains increasing importance when professional training is paradigmatically opposite [30].

\section{Results}

The mixed-method design yielded rich findings that will be discussed in light of how they reflect the two research questions. The first question being, "Are there differences and similarities between SW and FN graduate students regarding their attitudes and beliefs about disordered eating?"

\section{Qualitative}

There were both differences and similarities between the two groups regarding attitudes and beliefs to food. While portion sizes were determined externally, or by others, for both groups, what or who determined these differences was quite diverse. Industry, family, and culture determined what a normal portion size was for the SW students. FN students chose portion sizes according to Canada's Food Guide. The one similarity was in regard to portion size when eating outside the home. FN students stated they would eat a larger size portion when eating out, as compared to home, for reasons of financial practicality as highlighted by the participant statement, "I don't want to get gypped [sic]" [P12]. Likewise, the majority of SW students stated they would also eat the larger amount at a restaurant, trusting industry over their own view, to provide the normal portion, as demonstrated by the following quote, "I think in a restaurant they probably do give you the large size, and I'm ok with that" [P6].

There were differences upon the spectrum of tension experienced between the two groups of students when it came to portion size. A third of the SW students spoke of experiencing internal tension when the larger portion size was determined by a host when visiting outside of the home. Not to eat the portion size selected by the host equated to a sign of disrespect, and to do so risked being frowned upon by family members or relatives. To avoid experiencing a feeling of guilt, the larger portion would be consumed, resulting in a feeling of internal disconnect between hunger and familial approval made visible by this quote:

You have a little bit of everything and you have to make sure that your plate is full otherwise the host feels bad. It's not what your body needs, and it's not what's good for you ... it's more about how the host feels and you being a good guest ... [P2]. 
One of the SW participants described what happened when she chose the smaller portion size at the home of a family friend: "so they pulled me aside and they tell [sic] me ... you are actually insulting our host if you don't take more. You will eat the portion we give you, do you get it?"[P4]. The feeling of internal tension was described differently by the FN students. There was an absence of familial expectations regarding portion size. The tension was situated in the affective disconnect between what they desired to eat compared to what they actually ate. For example, the portion selected as the correct choice or normal portion based on Eating Well for Healthy Canadians [22] contradicted with the size they wanted to eat: "I love chicken fingers, but I guess being a nutrition student I know I would never order them [pause] ...." [P13].

There was a noticeable difference in language between the groups when discussing portion sizes. SW students tended to speak from a personal location using "I" statements, describing their choices affectively by stating that they ate the portion size that resulted in "feeling satisfied" or "healthier," even if was the largest portion size. This contrasted with the FN students who spoke in detached and clinical language, sometimes objectifying their choice. Their language was often constructed in a binary way separating them as a more knowledgeable group from the general population, as in "we are trained this way-we know better." Anyone other than food and nutrition students were referred to as: "normal people," "most people," or "other people." This binary categorization was made visible by one of the FN students who said, "as nutrition students, we obviously have a handle on this, but the general population has a distorted image of serving sizes and would disagree with us about the right serving size" [P11].

Conversely, there was no comparative component between the two groups regarding the theme of meal correction. In many cases the FN students would spontaneously offer suggestions on augmenting a photo in order to make it a "more complete meal" or a healthier serving. For example, in the case of the spaghetti photo, a common suggestion was to add a green salad, or similarly, to add fruit to the yogurt serving, whereas none of the social work students made such suggestions.

Explanations as to what represented a normal portion by the SW students emphasized certain groupings of words including:

- "I feel";

- "What I get in a restaurant, served in a restaurant, when I eat out";

- "The package tells you, the package does that for you, I don't have to make that decision";

- "Small is the right answer but I always order the large"; and

- "In my culture, they will put the food on the plate for you."

These word clusters were used for a second reiteration of the transcripts in order to arrive at themes grounded in the descriptions provided by the participants.

Explanations as to what represented a normal portion by the FN students emphasized certain groupings of words including:

- "According to Canada's Food Guide";

- "As a nutrition student ... for me the smallest one is normal- 


\section{JRIPE}

11

Social Work Students' Food Beliefs

McMillan \& Madill

Journal of Research in Interprofessional Practice and Education unfortunately it's not for most people";

- "I may be eating that (small portion) but I want that (large portion)"; and

- "What else are they eating for dinner? What else accompanies it? You could add a salad."

These word clusters were used for a second reiteration of the transcripts in order to arrive at themes grounded in the descriptions by the participants.

\section{Quantitative}

The Shapiro-Wilk test was used to determine normality and the Mann-Whitney was used as the data were not normally distributed. Continuous data were analyzed using independent $T$-test assuming unequal variances. Continuous variables are expressed as mean values \pm standard deviation. Categorical variables were analyzed using the chi-square statistical analysis with SPSS [31] $p$ denoted as $<0.05$. Prior to running statistical analysis, the authors made a decision to classify the results using the category of "rarely/never" to remain as unbiased as possible and avoid the assumption that the students who participated had eating disorders.

The mean age for the FN students was 24 years compared to a mean age of 34 for SW students. The average Body Mass Index (BMI) for FN students was $22 \mathrm{~kg} / \mathrm{m}^{2}$, whereas it was $34 \mathrm{~kg} / \mathrm{m}^{2}$ for SW students (see Table 4). The Eating Attitudes Test (EAT-26) is composed of three constructs; construct one includes all dieting subscale items, construct two identifies all bulimia and food preoccupation subscale items, and construct three is specific to oral control subscale items. Results are described in Tables 5 and 6 respectively.

\section{Table 4. Demographics of social work and food and nutrition students}

\begin{tabular}{|l|c|c|c|}
\hline & $\begin{array}{c}\text { Food and Nutrition } \\
(n=26)\end{array}$ & $\begin{array}{c}\text { Social Work } \\
(n=14)\end{array}$ & P value \\
\hline Age (years) & $24.1 \pm 4.1$ & $34.2 \pm 9.2$ & 0.001 \\
\hline Body Mass Index (BMI) kg/m² & $22.0 \pm 2.5$ & $27.8 \pm 8.8$ & 0.041 \\
\hline Physical Activity (PA) \% of participants & 4 & 14 & 0.136 \\
\hline Low & 54 & 71 & \\
\hline Moderate & 42 & 14 & \\
\hline High & 4 & & \\
\hline
\end{tabular}

Notes: Categorical data were analyzed using chi-square, $p<0.05$ was considered statistically significantly. Data were rerun with the single male student excluded, however significance did not change. 


\section{JRIPE}

Social Work Students' Food Beliefs

McMillan \& Madill
Table 5. EAT-26 - construct 1: Dieting subscale items for food and nutrition and social work students

\begin{tabular}{|l|c|c|c|}
\hline & $\begin{array}{c}\text { Food and Nutrition } \\
\text { (\% of respondents) }\end{array}$ & $\begin{array}{c}\text { Social Work } \\
\text { (\% of respondents) }\end{array}$ & $p$-VALUE \\
\hline Q1. I am terrified about being overweight. & 46 & 7 & 0.043 \\
\hline Q10. I feel extremely guilty after eating. & 76 & 14 & 0.006 \\
\hline Q11. I am preoccupied with a desire to be thinner. & 70 & 0 & 0.001 \\
\hline Q12. I think about burning up calories when I exercise. & 46 & 0 & 0.026 \\
\hline *022. I feel uncomfortable after eating sweets. & 55 & 7 & 0.031 \\
\hline Q23. I engage in dieting behaviour. & 73 & 18 & 0.013 \\
\hline
\end{tabular}

Notes: $* \%$ of respondents that indicated rarely/never as responses. Categorical data were analyzed using chi-square, $p<0.05$ was considered statistically significantly. Data were rerun with the single male student excluded, however significance did not change, except for Q22:"I feel uncomfortable after eating sweets."

\section{Table 6. EAT-26-construct 2: Bulimia and food preoccupation subscale} items for food and nutrition and social work students

\begin{tabular}{|l|c|c|c|}
\hline & $\begin{array}{c}\text { Food and Nutrition } \\
(\% \text { of respondents) }\end{array}$ & $\begin{array}{c}\text { Social Work } \\
\text { (\% of respondents) }\end{array}$ & $p$ - VALUE \\
\hline Q3. I find myself preoccupied with food & 35 & 7 & 0.039 \\
\hline $\begin{array}{l}\text { Q4. I have gone on eating binges where I feel that I } \\
\text { may not be able to stop }\end{array}$ & 81 & 36 & 0.025 \\
\hline $\begin{array}{l}\text { Q9. I vomit after I have eaten } \\
\text { Q21. I give too much time and thought to food }\end{array}$ & 100 & 57 & 0.003 \\
\hline
\end{tabular}

Notes: $* \%$ of respondents that indicated rarely/never as responses. Categorical data were analyzed using chi-square, $p<0.05$ was considered statistically significantly. Data were rerun with the single male student excluded, however significance did not change.

Overall, the FN students were younger and had lower BMIs than the SW students. Six SW students (43\%) were classified as Class III Obesity based on Health Canada [32], whereas no FN students met this criteria. Approximately 96 percent of FN students self-report they engage in moderate to high levels of exercise, similar to 85 percent of SW students.

EAT-26-construct 3: Oral control subscale items

There were no significant differences in the following questions: 2, 5, 8, 13, 19, and 20. 
These include the items: I avoid eating when I am hungry; I cut my food into small pieces; I feel that others would prefer if I ate more; Other people think that I am too thin; I display self-control around food; and, I feel that others pressure me to eat.

Lastly, the data collected regarding participant demographics reinforced the profile of those entering the professions of FN and SW. As mentioned, both are genderized professions as reflected in 98 percent of the study participants being female. The other variable that held true for the respective professions concerned age. Due to the value SW as a profession places upon field practice and experience, it is not surprising there was a six-year difference in age between the oldest SW and FN students. Although marital status and ethnicity were not asked on the demographic form, many of the SW participants spoke of their roles as wives and mothers, in addition to cultural norms and expectations, and how this lens informed their choices regarding portion selection. In a sub-group analysis, social work students were compared by age and BMI. Students with BMI $>30 \mathrm{~kg} / \mathrm{m}^{2}$ were significantly older (mean age: $41 \pm 5$ years) compared to those who had BMI $<30 \mathrm{~kg} / \mathrm{m}^{2}[(25 \pm 2.8$ years $) p=0.001]$.

\section{Discussion}

The similarities and differences between the FN and SW students informed our second research question, "What do the descriptions on food portions tell us about these similarities and differences between the two professions?"

The impact of how an older lifecycle stage may contribute to beliefs and attitudes around food is unknown and suggests the need for further study. In a study by Szweda and Thorne [17] examining nursing, medical, and arts students, the authors found no differences between the three groups regarding eating disordered behaviours. This raises the question of why significant differences were found in our study between FN and SW students, specifically in construct 2 regarding the question, "I find myself preoccupied with food." This preoccupation manifested differently between the two student groups, with the SW students eating their desired portion, unlike FN students who denied themselves the larger portion. This might possibly explain the considerable differences regarding BMI between the two groups of students.

Although the diverse paradigms of teaching and practice (science and social science) were noted, a shared similarity between the two groups reflected the concept of tension. FN students spoke of internal tension resulting in smaller portions, versus the SW students who described external tension resulting in larger portions. This suggests that within our study the concept of tension lies upon a spectrum, but manifested differently between the two student groups. Extending this possibility further, it was noted that six of the SW students were classified as obese based upon Health Canada criteria [32] whereas FN students did not fit this description. One possible explanation is that external pressure coming from family and cultural expectations resulted in the SW students eating, or eating more, when not hungry.

We also found several interesting parallels between the food and nutrition students in our study with one conducted in Brazil by Luiza do Nascimento Ghizoni Pereira [14] involving 214 health science students, including nutrition students but 
14

Social Work Students' Food Beliefs

McMillan \& Madill

Journal of Research in Interprofessional Practice and Education

Vol. 6.2

2016 not social work students. When comparing our study with Pereira's results, there was a close relationship between the age of FN participants ( 24 versus 21 years) and BMI (22 versus $21 \mathrm{~kg} / \mathrm{m}^{2}$ ) respectively. Conversely, the results differed regarding restrictive behavioural activities, where approximately 73 percent of nutrition students expressed wanting to weigh less. One possible reason for the high percentage in restrictive behaviours suggested by the previous authors was that food and nutrition students belong to an occupational group that "reinforces the demand for a very thin body" [14, p. 18]. However, our study reported only 30 percent of the food and nutrition students desired to be thinner, unlike the 100 percent of the social work students that indicated wanting to weigh less. We could speculate that these differences could simply be a result of cultural variations; however, we did not examine this and thus this difference warrants further cross-cultural inquiry.

Of interest is that 50 percent of food and nutrition students reported they were terrified about being overweight (see Table 5, Q1) and 50 percent reported that they think about burning calories when exercising (see Table 1, Q12); this was reflected in 42 percent reporting high levels of physical activity. Similarly, Pereria [14] indicated that 78 percent of female nutrition students reported body dissatisfaction. In contrast to this, 93 percent of social work students were terrified of being overweight, 100 percent thought about burning calories when exercising, but only 14 percent reported high levels of physical activity. It is plausible that this discrepancy in the activity level represents environmental issues since social work students were older with family and financial obligations, possibly preventing them from engaging in higher activity levels. Taken together, these studies raise the idea that perhaps these professions attract students who have problematic eating behaviours. Alternatively, there may be other external factors, resulting in the high prevalence of anorexia and bulimic tendencies. This concept also relates to our second research question aimed at obtaining a better understanding of the two student populations that express the desire or intent to work within the eating disorder population upon graduation.

An area where quantitative results confirmed the qualitative findings was in construct 3: oral control subscale. Ninety-six percent of the food and nutrition students answered affirmatively that they always displayed self-control around food. Participant statements confirmed this during the focus groups in the way they spoke of eating only half portions with several food items, including juice, yogurt, bagels, and French fries. This is exemplified by one FN student's comment on banana cake: "it reminds me of something you order and when it comes it's like 4 inches high, and I look at the plate and think God [pause] I can't eat that" [P23].

Furthermore, we also speculate on the values that are reinforced in the curriculum between the professions. FN pedagogy focuses on healthy eating and physical activity, unlike SW where the focus is on healthy relationships with family and others.

\section{Limitations}

We acknowledge that our study does have some limitations. A demographic question on the marital status and culture of the participants would have provided additional information, specifically for the SW students whose explanations often included 
both of these factors as contributing reasons to eat when not hungry. For example, we question how being older with family obligations influenced their answers. Additionally, the voluntary nature of the focus groups may have resulted in a selection bias of those who volunteered for the study. Nevertheless, we feel these findings are of interest since we are unaware of any previous cross-comparative study between FN and SW students regarding attitudes and beliefs toward food and eating.

\section{Conclusion}

There are no similar studies documented in the literature. Understanding pre-existing attitudes and beliefs concerning food and eating by students planning to work in the area of eating disorders raises questions of possible professional competence and practice upon entering this specialty area. The development and offering of curriculum that speaks to the importance of self-awareness may also be helpful in training students who want to work with this population as healthcare providers upon graduation.

\section{Implications for practice and education}

It has been reported in the literature that individuals working in healthcare where empathy and person-centred care is the norm experience higher than normal degrees of stress and compassion fatigue [33]. This is especially relevant in the two professions of SW and FN students, as the benchmark of practice raises the possibility of whether students who exhibit eating disorder tendencies are adequately prepared for responding to such stresses both on a patient and team level. Furthermore, employment role descriptions may exacerbate prodrome eating disorder tendencies among new graduates. The Butterfly Foundation for Eating Disorders states that the role of a dietitian on a team is to "help individuals recognise feelings associated with hunger and satiety and discuss appropriate behavioural responses" [34, p. 17]. Yet, a key finding resulting from the food and nutrition student group in this study was the internal tension and incongruence that existed between responding to hunger by choosing a smaller portion size. How to reconcile the personal portion size tension within a professional role warrants greater exploration within the current curriculum, prior to entering a career working in an eating disorder setting. Similarly, studies have documented that mental health professionals who work with eating disordered patients experienced intense feelings of stress, hostility, anger, and hopelessness [35-39]. Building on this background, published over 20 years ago, we were unable to find any studies addressing this issue or how this will impact the two professions. Similarly, studies have documented that mental health professionals who work with eating disordered patients experienced intense feelings of stress, hostility, anger and hopelessness. However we were unable to find any current studies addressing these feelings or how this will impact the two professions. Therefore, the clinical implications of this require further investigation.

Another implication relates to how the concept of tension is displayed differently between the two student groups. How these manifestations are played out within an interprofessional team context and inform patient-case management decisions speaks to the importance of further study. The high occurrence of conflict on inter- 
16

Social Work Students' Food Beliefs

McMillan \& Madill
Journal of Research in Interprofessional Practice and Education

Vol. 6.2

2016 professional teams is well documented [40]. Positioning this high occurrence alongside the challenges of treating eating disorders poses a serious pedagogical and clinical training dilemma for new graduates. How do educators prepare and support students who display problematic tendencies around food and eating prior to entering the field? Our study opens up a space to emphasize the importance of interprofessional learning and for educators in both professions to assume a leadership role. As both academics and practitioners, we offer several options: a mandatory course on self-awareness and personal/professional reflection, an interprofessional training module between FN and SW students, and lastly, the realization that existing pedagogy obscures problematic beliefs and attitudes toward food and eating, not unlike the etiology of eating disorders.

\section{Acknowledgements}

The authors are grateful to all participants who so generously shared their time and interest in our study. Furthermore, we acknowledge the hard work and dedication of our peer-research assistants Amanda Jenkins, Ana Stanivuk, Grace Warmels, Lauren Murch, and Brooke Bliss.

\section{References}

1. Ministry of Health and Long Term Care. (2006). McGuinty government invests in eating disorder treatment programs. URL: https://news.ontario.ca/archive/en/2006/02/08/McGuinty-Government -Invests-In-Eating-Disorder-Treatment-Programs.html [January 16, 2016].

2. Dziegielewski, Sophia, F. (2013). The Changing Face of Health Care Social Work. New York, NY: Springer Publishing.

3. Ko, Nayeong, Tam, Minh, Duong, Viet, Nguyen,Kim, Scheib, Peter, Wirsching, Michael, \& Zeeck, Almut. (2015). Disordered eating behaviors in university students in Hanoi, Vietnam. Journal of Eating Disorders, 3(1), 18.

4. Berry, Tanya, R., \& Howe, Bruce, L. (2000). Risk factors for disordered eating in female university athletes. Journal of Sport Behavior, 23(3), 207-218.

5. Reinstein, Nancy, Koszewski, Wanda, M., Chamberlin, Barbara, \& Smith-Johnson, Cynthia. (1992). Prevalence of eating disorders among dietetics students: Does nutrition education make a difference? Journal of the American Dietetic Association, 8, 949-953.

6. Kiziltan, Gul, \& Karabudak, Efsun. (2008). Risk of abnormal eating attitudes among Turkish dietetic students. Adolescence, 43, 171.

7. Atkins, Jacqui, \& Gingras, Joanne. (2009). Coming and going: Dietetic students' experience of their education. Canadian Journal of Dietetic Practice and Research: A Publication of Dietitians of Canada, 70(4), 181-186.

8. Gonidakis, Fragiskos, Sigala, A., Varsou, Eleytheria, \& Papadimitriou, George. (2009). A study of eating attitudes and related factors in a sample of first year female nutrition and dietetics students of Harokopion University in Athens, Greece. Eating Weight Disorders, 14, 2-3.

9. Arroyo, Marta, Basabe, Nekane, Serrano, L., Sanchez, C., Ansotegui, L., \& Rocandio, Ana, M. (2010). Prevalence and magnitude of body weight and image dissatisfaction among women in dietetics majors. Archivos Latinoamericanos de Nutricion, 60(2), 126-132.

10. Drummond, Dianne, Hare, M., Stephanie. (2012). Dietitians and eating disorders: An international issue. Canadian Journal of Dietetic Practice and Research, 73(2), 86-90.

11. Mahn, Heather, M., \& Lordly, Daphne. (2015). A review of eating disorder and disordered eating amongst nutrition student and dietetic professionals. Canadian Journal of Dietetic Practice and Research, 76(1), 38-43.

12. Kolka, Magdalena, \& Abayomi, Julie. (2012). Body image dissatisfaction among food?related degree students. Nutrition \& Food Science, 42(3), 139-147.

13. Abrams, Kay, K., Allen, La Rue, R., \& Gray, James, J. (1993). Disordered eating attitudes and behaviors, psychological adjustment, and ethnic identity: A comparison of black and white female college students. International Journal of Eating Disorders, 14(1), 49-57. 
17

Social Work Students' Food Beliefs

McMillan \& Madill

Journal of Research in Interprofessional Practice and Education

Vol. 6.2

2016
14. Pereira, Luizado Nascimento Ghizoni, Trevisol, Fabiana, S., Quevedo, Joao, \& Jornada, Luciano, K. (2011). Eating disorders among health science students at a university in southern Brazil Transtornos alimentares em universitárias da área da saúde de universidade do sul do Brasil. Trends in Psychiatry and Psychotherapy, 33(1), 14-19.

15. Howat, Paula, M., Beplay, Stephanie, Wozniak, Patricia. (1993). Comparison of bulimic behavior incidence by profession: Dietitian, nurse, teacher. Journal of Nutrition Education, 25(2), 67-69.

16. Mealha, Vanessa, Ferreira, Caterina, Guerra, Ines, \& Ravasco, Paula (2013). Students of dietetics \& nutrition; a high risk group for eating disorders? Nutrición Hospitalaria, 28(5), 1558-1566.

17. Szweda, Stephen, \& Thorne, Pam. (2002). The prevalence of eating disorders in female health care students. Occupational Medicine, 52(3), 113-119.

18. Reiter, Christer, S., \& Graves, Leah. (2010). Nutrition therapy for eating disorders. Nutrition in Clinical Practice, 25(2), 122-136.

19. Navarro, Leyla, \& Schwartzberg, Sharon, L. (2007). Envy, competition and gender: Theory, clinical applications and group work. London, UK: Routledge.

20. Tashakkori, Abbas, \& Creswell, John, W. (2007). Exploring the nature of research questions in mixed methods research. Journal of Mixed Methods Research, 1(3), 207-210.

21. Teddlie, Charles, \& Tashakkori, Abbas (2009). Foundations of mixed methods research: Integrating quantitative and qualitative approaches in the social and behavioral sciences. Thousand Oaks, CA: Sage Publications.

22. Health Canada. (2011). Nutrition. URL: http://hc-sc.gc.ca/fn-an/nutrition/index-eng.php [April 17, 2017].

23. Garner, David., \& Garfinkel, Peter, E. (1979). The eating attitudes test: An index of the symptoms of anorexia nervosa. Psychological Medicine, 9, 273-279.

24. Garner, David, Olmsted, Marion, Bohr, Yvonne, \& Garfinkel, Paul, A. (1982). The eating attitudes test: psychometric features and clinical correlates. Psychological Medicine, 12(4), 871-878.

25. Garner, David M., Rosen, Larry, \& Barry, David (1998). Eating disorders among athletes. Research and recommendations. Child and Adolescent Psychiatric Clinics of North America, 7(4) 839-857.

26. Cotton, Mary-Anne, Ball, Christopher, \& Robinson, Paul (2003). Four simple questions can help screen for eating disorders. Journal of General Internal Medicine, 18(1), 53-56.

27. Bailey, Julia (2008). First steps in qualitative data analysis: Transcribing. Family Practice, 25(2), 127-131.

28. Borkan, Jeffrey (1999). Immersion/crystallization. In Benjamin F. Crabtree, \& William L. Miller (Eds.), Doing qualitative research, 2nd edition (pp. 179-194). Thousand Oaks, CA: Sage Publications.

29. Crabtree, Benjamin, F., \& Miller, William, L. (Eds.) Doing qualitative research (first edition). Newbury Park, CA. Sage Publication.

30. Mauthner, Natasha, S., Parry, Odette, \& Backett-Milburn, Kathryn (1998). The data are out there, or are they? Implications for archiving and revisiting qualitative data. Sociology, 32, 733-745.

31. IBM Corp. Released 2014. IBM SPSS Statistics for Windows, Version 23.0. Armonk, NY: IBM Corp.

32. Body Mass Index [BMI]. BMI chart. URL: http://www.hc-sc.gc.ca/fn-an/nutrition/weights -poids/guide-ld-adult/bmi_chart_java-graph_imc_java-eng.php [April 17, 2017].

33. Morse, Gary, Salyers, Michelle, Rollins, Angela, Monroe-DeVita, Maria, \& Pfahler, Corey (2012). Burnout in mental health services: A review of the problem and its remediation. Administration and Policy in Mental Health and Mental Health Services Research, 39(5), 341-352.

34. Butterfly Foundation of Eating Disorders. (2012). Paying the price. The economic and social impact of eating disorders in Australia. URL: http://thebutterflyfoundation.org.au/wpcontent/uploads /2012/12/Butterfly_Report.pdf [February 4, 2016].

35. Frankenberg, Frances, R. (1984). Female therapists in the management of anorexia nervosa. International Journal of Eating Disorders, 3(4), 25-33.

36. Garner, David, M. (1984). Iatrogenesis in anorexia nervosa and bulimia nervosa. International Journal of Eating Disorders, 4(4), 701-726.

37. Jones, Dorothy, M. (1985). Bulimia: A false self-identity. Clinical Social Work Journal, 13, 305-316.

38. Johnson, Craig, \& Connors, Mary. (1987). The etiology and treatment of bulimia nervosa. New York, NY: Basic Books.

39. Manley, Ron, \& Becker, William E. (2005). “No, I can't be your...” Boundary issues for health care professionals. British Columbia Medical Journal, 47(1),41-43.

40. Brown, Judith Belle, Lewis, Laura, Ellis, Kathy, Stewart, Moira, Freeman, Thomas R., \& Kasperski, Janet (2011). Mechanisms for communicating within primary health care teams. Canadian Family Physician, 55(12), 1216-1222. 